\title{
Phenotypic antimicrobial resistance in Escherichia coli strains isolated from swine husbandries in North Western Germany - temporal patterns in samples from laboratory practice from 2006 to 2017
}

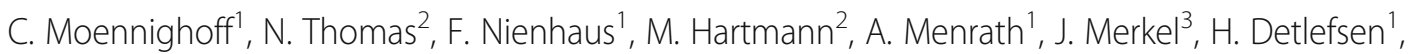 \\ L. Kreienbrock ${ }^{2}$ and I. Hennig-Pauka ${ }^{1 *}$ (D)
}

\begin{abstract}
Background: Since 2011, antibiotic usage has decreased continuously in livestock in Germany. Whether this is accompanied by a reduction in bacterial antimicrobial resistance has not been proven so far. In this study 3054 Escherichia coli (E. coli) isolates from pigs which had suffered from disease on 2161 farms in North Western Germany were evaluated retrospectively from 2006 to 2017 for trends in their antimicrobial resistance pattern. Data were substantially related to the "pre-reduction period" and were therefore suggested as a basis for this task.

Minimal inhibitory concentrations for selected antimicrobial substances were evaluated for $E$. coli strains isolated from different organs of diseased swine sampled for routine diagnostic. In total, $81 \%$ of $E$. coli were isolated from faeces or the gastrointestinal tract, $11 \%$ from the genito-urinary tract and $8 \%$ from other organs. Susceptibility testing and classification of isolates in accordance with clinical cut-offs followed the Clinical and Laboratory Standards Institute (CLSI). If no clinical cut-offs were available for the respective combination of species, substance and organ, other published clinical cut-offs were used.

Results: Differences in susceptibility patterns between isolates from the gastrointestinal and genito-urinary tract were found for most substances. Isolates from the genito-urinary tract were less frequently resistant to ampicillin, apramycin, colistin, neomycin, spectinomycin and tetracycline and more frequently resistant to enrofloxacin and florfenicol. A multifactorial logistic regression model revealed time-dependent decreases in frequency of resistant isolates for neomycin, spectinomycin and tetracycline. For colistin, the highest percentage of resistant isolates with $16.0 \%$ was found in 2015 followed by a decrease to the level of 2009-2010 in 2017. A decrease in frequencies of ampicillinresistant isolates was dependent on the age-group and time period. Irrespective of the year, less than $15 \% \mathrm{E}$. coli isolates were resistant to apramycin, cephalosporins, colistin, enrofloxacin, florfenicol, gentamicin and neomycin.

Conclusion: An overall time-dependent decrease in the percentage of resistant $E$. coli isolates was found for some substances. These data from diseased animals indicate an impact of a general reduction in antibiotic usage on development of bacterial antimicrobial resistance in the field and can support the decision-making of swine practitioners for treatment options in swine.
\end{abstract}

Keywords: Routine data, Minimal inhibitory concentration, Pig production, Epidemiology

\footnotetext{
* Correspondence: Isabel.Hennig-Pauka@tiho-hannover.de

${ }^{1}$ Field Station for Epidemiology in Bakum, University of Veterinary Medicine

Hannover, Hanover, Germany

Full list of author information is available at the end of the article
}

(c) The Author(s). 2020 Open Access This article is distributed under the terms of the Creative Commons Attribution 4.0 International License (http://creativecommons.org/licenses/by/4.0/), which permits unrestricted use, distribution, and reproduction in any medium, provided you give appropriate credit to the original author(s) and the source, provide a link to the Creative Commons license, and indicate if changes were made. The Creative Commons Public Domain Dedication waiver (http://creativecommons.org/publicdomain/zero/1.0/) applies to the data made available in this article, unless otherwise stated. 


\section{Background}

The development of antimicrobial resistance (AMR) is a natural phenomenon in bacteria. Nonetheless, antibiotic treatment either in the recommended dosage, under- or overdosed is triggering the global expansion of AMR due to shifts towards more resistant bacterial populations $[1,2]$. In the human health care sector, a close link between the frequency of antibiotic usage and the prevalence of resistant bacteria exists $[3,4]$. This association was also shown for livestock animals, which has a high impact on consumer protection due to the cross-linking of animal and human bacterial reservoirs [5]. Epidemiological studies revealed either an increase in antimicrobial resistance in populations treated more often with antibiotics [6, 7], or a beneficial effect on resistance levels after the introduction of national antimicrobial usage (AMU) reduction campaigns [8]. Under defined experimental conditions, the effect of a selective pressure by antimicrobial usage on the frequency of phenotypically resistant bacteria in swine [9] or the total resistome of bacterial populations [10] was proven. In general, under field conditions, in livestock, the association between AMU and AMR is difficult to assess because additional factors such as vaccination, feed supplements, hygiene conditions and management characteristics also have an impact [11]. In a European study, farm-specific faecal antimicrobial resistomes defined in a metagenomic approach revealed a clear association between usage of tetracyclines and macrolides with the respective resistance genes, while for other widely used substances, no associations were found [12]. In a longitudinal study on one pig farm, the elimination of $E$. coli carrying the mobile $m c r-1$ gene coding for colistin resistance was achieved within a 20-month period after stopping colistin treatment [13].

In order to monitor the development of AMR continuously, several surveillance programmes have been implemented in Europe. In particular, both, the transnationally acting Global Antimicrobial Resistance Surveillance System (GLASS) and the European Antimicrobial Resistance Surveillance System (EARSS) as well as national programmes in the different countries record antimicrobial resistance in bacteria as well as the amount of antibiotics used in animals at different levels, i.e. animals, food and humans.

The collection of farm-level AMU data in different European countries revealed country-specific differences in reported variables, so that data are difficult to compare. In a recent study in nine European countries, overall, AMU was highest in weaners, the majority being administered in feed or water, the most frequent specific treatment indications being intestinal and respiratory disorders [14]. Indications and used antimicrobial substances varied between countries and different age groups $[15,16]$. In Germany, data of antimicrobial consumption and resistance in bacteria have been systematically available since 2008 [17]. These data derive from passive surveillance reporting information from 2008,
2010, 2012 and 2015. Since 2011, pharmaceutical companies have had to report the quantities of antibiotics dispensed per year in accordance with the German Pharmaceuticals Act [18] and the DIMDI-Ordinance [19] on Medicinal Products. In 20111706 tons of antimicrobial agents were delivered. The most widely given active ingredients were tetracyclines (564 tons), aminopenicillins (528 tons), sulfonamides (185 tons) and macrolides (173 tons). The indication" respiratory disease" was recorded most frequently in weaners and sows and mainly treated with amoxicillins and tetracyclines [20]. In addition, in sows, reproductive and fundamental disorders were main causes for antibiotic treatment. Reproductive disorders were mainly treated with tetracyclines, followed by amoxicillin [20]. In comparison with 2011, the amount of antimicrobials sold more than halved in 2017 [16]. Also, with regard to treatment frequency in 2011, 2013 and 2014, a clear reduction was observed in German pig holdings [21, 22]. In the years 2013-2015, fatteners were mainly treated with tetracyclines and penicillines, accounting for $60 \%$ of antibiotic treatments, while in weaners, amoxicillin and colistin were most often used [22]. In suckling piglets, treatments with macrolides and penicillines were most frequent [22]. Obligatory monitoring of the usage of antibiotic substances in fattening pigs and weaners, as well as in poultry and beef cattle was enforced in the 16th Amendment of the German Pharmaceuticals Act in 2014 [18]. Since then, antibiotic usage data of swine have been collected in a central database and the treatment frequency for the respective farm is calculated, being compared with the countries' median and sanctioned if exceeding the upper quartile value [23].

Due to the general nature of these data, so far, linking AMU to frequencies of AMR is not possible [24], and much more specialised livestock information is needed [25]. For assessing antibacterial resistance data from the field, the various resistance mechanisms in different bacterial species must be taken into account [26-28].

The Field Station for Epidemiology of the University of Veterinary Medicine Hannover, Germany is a diagnostic institute located in a swine-dense region in the North Western part of Germany. Since 2006, data of AMR resistance in swine pathogens have been recorded in an institutional database. By using descriptive and inductive statistical methods 3054 data for E. coli originating from diseased pigs were evaluated in this study at yearly intervals. The hypothesis behind evaluating routine data was that pronounced changes in AMR over the years in parallel to an observed reduction in AMU would become detectable in a field population.

\section{Results}

Distribution of antimicrobial resistance

The E. coli isolates originated from diseased pigs from 2161 farms in a period from 2006 to 2017. 
In total, frequencies of resistant isolates below $6 \%$ were found for cefquinome, ceftiofur, gentamicin, apramycin, florfenicol and enrofloxacin. Highest frequencies above $70 \%$ of resistant isolates were found for ampicillin and tetracycline as shown in Table 1. While more than $96 \%$ of the isolates were susceptible to third- and fourthgeneration cephalosporins, i.e. ceftiofur and cefquinome, this was only the case for $57 \%$ of the isolates with respect to the first-generation cephalosporin, cephalothin, with a high percentage of intermediate isolates, namely $33 \%$.

The distribution of MICs of respective E. coli isolates is depicted in Table 1. The MICs for most antimicrobial agents were unimodally distributed. MICs for apramycin, cefquinome, ceftiofur, colistin, enrofloxacin, gentamicin and neomycin showed a unimodal left-skewed distribution, indicating low MICs of mainly susceptible isolates. Interquartile ranges of MICs in the different years were narrow for substances with high susceptibility (e.g. ceftiofur/cefquinome $0.5-0.5 \mathrm{mg} / \mathrm{L}$, gentamicin $1-1 \mathrm{mg} / \mathrm{L}$, neomycin/apramycin 4-4 mg/L, enrofloxacin $0.03-0.03$ $\mathrm{mg} / \mathrm{L}$, colistin $0.25-0.25 \mathrm{mg} / \mathrm{L}$ ) or with a high resistance rate in $E$. coli (e.g. tetracycline $32-32 \mathrm{mg} / \mathrm{L}$ ). Wider interquartile ranges in MICs were found for ampicillin (8-64 mg/L) and spectinomycin (16-128 mg/L). Spectinomycin MICs were bimodally distributed with more than $30 \%$ of the isolates having MICs of 16 or lower, while $20 \%$ of the isolates were characterised by an MIC of 256. Cephalothin, florfenicol and spectinomycin could not be classified according to their MIC distribution and many isolates were classified as intermediate.

Assessment of susceptibility of isolates according to epidemiological cut-offs resulted in slightly different frequencies of resistant isolates, which were in almost all cases higher or equal to those assessed by clinical cut-offs (Table 1).

\section{Comparison of isolates from different sampling sites and age-groups}

The sampling site as well as age-group were significant factors influencing the relative frequencies of resistant isolates. For that reason, single comparisons (chi-square test) as well as simple and multifactorial logistic regression models were used to elucidate the impact of the factors time period, age-group and sampling site on the frequencies of resistant isolates. Absolute and relative frequencies of isolates from different sampling sites are shown in Table 10. While the percentage of age-groups within the data subset of 956 animals did not change over time, the percentage of samples from the gastrointestinal and the genito-urinary tract $(n=2809)$ differed in the observed time periods with approximately $14 \%$ of samples from the genito-urinary tract in 2006-2011 and only $8 \%$ from the period 2012-2017 $(p<0.0001)$ (data not shown). Lower frequencies of resistant isolates were found in the genito-urinary tract for ampicillin, apramycin, colistin, neomycin, spectinomycin and tetracycline. In contrast to that, higher frequencies of resistant isolates in the genito-urinary in comparison to the gastrointestinal tract were found for enrofloxacin and florfenicol (Tables 2, 3, 4, and 5, Additional file 1f-g).

In sows, $78.9 \%$, and in all other age-groups, only $0.1-$ $4.0 \%$ samples originated from the genito-urinary tract, so that age-dependent differences might also reflect sampling-site specific differences (Table 10). Indeed, in the data set containing 956 animals of known agegroups, similar findings were found for sows as for genito-urinary tract samples compared to the data pool of piglets, nursery and fattening pigs. In sows, the percentage of isolates resistant to ampicillin $(63.2 \%$ vs. $77.8 \%, p=0.05)$, colistin (3.3\% vs. $17.9 \%, p=0.5)$ and neomycin $(0.0 \%$ vs. $14.1 \%, p=0.01)$ were less and that of isolates resistant to enrofloxacin, $(17.1 \%$ vs. $1.8 \%, p<$ 0.0001) was more frequent (data not shown).

\section{Temporal trends in AMR}

The relative frequency of resistant isolates in the different years from 2006 to 2017 is shown in Fig. 1 indicating several levels of AMR.

To address the hypothesis that reduction in antibiotic usage since 2011 had an influence on bacterial resistance development, the two six-year time periods from 2006 to 2011 and 2012-2017 were compared by means of the chi-square test as well as in one-factorial and multifactorial logistic regression models. A higher percentage of resistant isolates was found for all cephalosporins, colistin, enrofloxacin and gentamicin in the time period 2012-2017, while decreases were found for tetracycline, spectinomycin and neomycin. Regarding only isolates from the gastrointestinal tract, therefore excluding bias by different sampling sites resulted in similar trends for colistin, gentamicin, neomycin, spectinomycin and tetracycline (data not shown). Findings were specified by simple regression models comparing findings in single years to the allocation base 2011 (data not shown).

A multifactorial logistic regression model was performed for comparing both time periods, simultaneously taking factors age-group and sampling site into account. While differences in frequencies of resistant isolates with respect to cefquinome, ceftiofur and colistin were due to age-group (Additional files 1b-c, e), differences with regard to neomycin, spectinomycin and tetracycline were related to the time periods (Tables 2, 3 and 4).

Differences with respect to ampicillin were significantly due to age-group and time (Table 5). The sampling site had no significant influence in this model.

The percentage of neomycin- (18.4 to $17.9 \%)$, spectinomycin- (34.5 to $22.6 \%)$, tetracycline- (84.2 to $60.5 \%)$ and ampicillin-resistant (74.5 to $66.1 \%)$ isolates decreased from 2006 to 2017 (Tables 6, 7, 8 and 9). The 


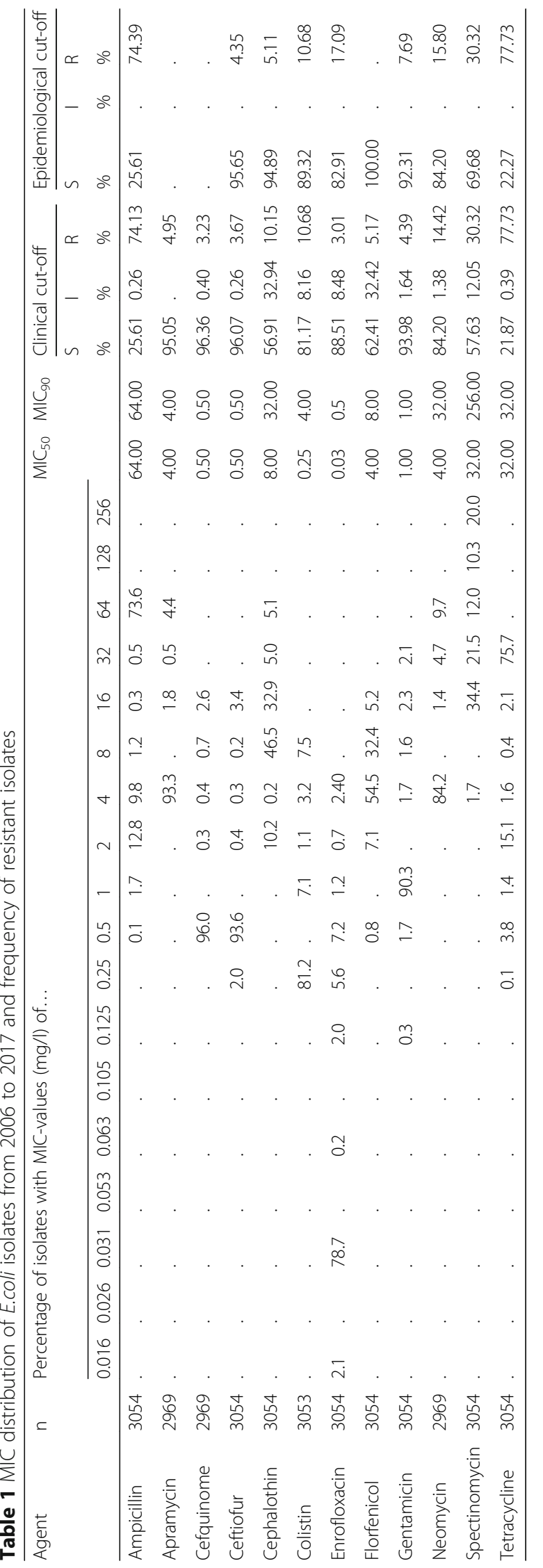


Table 2 Neomycin resistance

\begin{tabular}{|c|c|c|c|c|c|c|c|c|c|}
\hline & & \multicolumn{2}{|c|}{ Resistant isolates } & \multicolumn{2}{|c|}{ Susceptible isolates } & \multicolumn{2}{|c|}{ One-factorial log. Reg. } & \multicolumn{2}{|c|}{ Multi-factorial log. Reg } \\
\hline & & $n$ & $\%$ & $n$ & $\%$ & $\overline{O R}$ & $p$ & $\mathrm{OR}$ & $p$ \\
\hline \multirow[t]{2}{*}{ Time period } & 2006-2011 (Ref.) & 280 & 15.77 & 1496 & 84.23 & 1 & - & 1 & - \\
\hline & 2012-2017 & 148 & 12.85 & 1004 & 87.15 & 0.79 & 0.029 & 0.60 & 0.011 \\
\hline \multirow[t]{4}{*}{ Age-group } & Sow (Ref.) & 0 & 0 & 35 & 100 & 1 & - & 1 & - \\
\hline & Piglet & 17 & 12.98 & 114 & 87.02 & - & 0.949 & - & 0.951 \\
\hline & Nursery & 100 & 14.66 & 582 & 85.34 & - & 0.949 & - & 0.950 \\
\hline & Fattening & 4 & 9.09 & 40 & 90.91 & - & 0.949 & - & 0.953 \\
\hline \multirow[t]{3}{*}{ Sampling site } & GIT (Ref.) & 363 & 15.35 & 2002 & 84.65 & 1 & - & 1 & - \\
\hline & GUT & 25 & 7.69 & 300 & 92.31 & 0.46 & 0.0003 & - & 0.958 \\
\hline & others & 40 & 16.81 & 198 & 83.19 & 1.11 & 0.554 & - & 0.857 \\
\hline
\end{tabular}

development of frequencies of resistant isolates to other antimicrobials throughout the years are shown in Additional file $2 \mathrm{a}-\mathrm{h}$. With respect to epidemiological cut-offs, similar trends were observed. While time-dependent decreases were found for frequencies of resistant isolates with respect to neomycin, spectinomycin and tetracycline, additionally, a significant age-group related increase in enrofloxacin-resistant isolates (15.2 to 16.1\%) from 2006 to 2017 was observed $(p=0.002)$ (Data not shown).

Tables 2, 3, 4 and 5 Multifactorial logistic regression analysis with fixed effect time period and factors "age-group" and "sampling site" with respect to neomycin (2), spectinomycin (3), tetracycline (4) and ampicillin resistance (5). Reference categories for the logistic regression method (time period 2006-2011, sow, gastrointestinal tract) are highlighted in bold and indicated by "Ref.". One-factorial log. Reg.: Onefactorial logistic regression model, Multi-factorial log.reg.: Multi-factorial logistic regression model, OR: Point estimate /Odds ratio, $\mathrm{p}: p$-value of the Wald test, $\mathrm{n}$ : absolute number of isolates, \%: percentage of isolates.

\section{Discussion}

In this study, based on routine diagnostic data from swine farms in a swine-dense region in North Western Germany, antimicrobial resistances were analysed for $E$. coli isolated in a diagnostic institute between 2006 and 2017. All isolates originated from diseased animals and the data set was restricted to one isolate from one farm per year.

In general, studies dealing with bacterial resistance focus on either i) analysis of routine data as was the case in this study, ii) standardised experiments and epidemiological studies or iii) resistance monitoring following a statistically valid sampling programme $[29,30]$. Secondary data from daily routine as used in the present analyses are prone to different types of bias. This is mainly due to the non-standardised and non-representative sampling of diseased animals and the lack of metadata, which leads to a confounding bias in the results.

Samples originated from the North Western part of Germany might therefore not be representative of the whole of Germany and therefore might be prone to a selection bias. Nevertheless, more than half of the German swine population is located in this region, so that findings are of importance for the whole country. Moreover, regional differences in antimicrobial use were not recorded for Germany [20, 21].

Due to high standardisation of the routine susceptibility testing of isolates throughout the years, an information

Table 3 Spectinomycin resistance

\begin{tabular}{|c|c|c|c|c|c|c|c|c|c|}
\hline & & \multicolumn{2}{|c|}{ Resistant isolates } & \multicolumn{2}{|c|}{ Susceptible isolates } & \multicolumn{2}{|c|}{ One-factorial log. Reg. } & \multicolumn{2}{|c|}{ Multi-factorial log. Reg. } \\
\hline & & $\mathrm{n}$ & $\%$ & $\mathrm{n}$ & $\%$ & OR & $p$ & OR & $p$ \\
\hline \multirow[t]{2}{*}{ Time period } & 2006-2011 (Ref.) & 618 & 39.09 & 963 & 60.91 & 1 & - & 1 & - \\
\hline & 2012-2017 & 308 & 27.87 & 797 & 72.13 & 0.60 & $<0.0001$ & 0.62 & 0.003 \\
\hline \multirow[t]{4}{*}{ Age-group } & Sow (Ref.) & 8 & 22.22 & 28 & 77.78 & 1 & - & 1 & - \\
\hline & Piglet & 39 & 312 & 86 & 68.8 & 1.59 & 0.300 & 1.93 & 0.422 \\
\hline & Nursery & 206 & 32.09 & 436 & 67.91 & 1.65 & 0.220 & 1.76 & 0.489 \\
\hline & Fattening & 13 & 31.71 & 28 & 68.29 & 1.62 & 0.354 & 1.76 & 0.512 \\
\hline \multirow[t]{3}{*}{ Sampling site } & GIT (Ref.) & 783 & 36.23 & 1378 & 63.77 & 1 & - & 1 & - \\
\hline & GUT & 79 & 25.73 & 228 & 74.27 & 0.61 & 0.0003 & 1.220 & 0.8104 \\
\hline & others & 64 & 29.36 & 154 & 70.64 & 0.73 & 0.044 & 0.685 & 0.1871 \\
\hline
\end{tabular}


Table 4 Tetracycline resistance

\begin{tabular}{|c|c|c|c|c|c|c|c|c|c|}
\hline & & \multicolumn{2}{|c|}{ Resistant isolates } & \multicolumn{2}{|c|}{ Susceptible isolates } & \multicolumn{2}{|c|}{ One-factorial log. Reg. } & \multicolumn{2}{|c|}{ Multi-factorial log. Reg. } \\
\hline & & $\mathrm{n}$ & $\%$ & $\mathrm{n}$ & $\%$ & OR & $\mathrm{p}$ & OR & $p$ \\
\hline \multirow[t]{2}{*}{ Time period } & 2006-2011 (Ref.) & 1492 & 82.98 & 306 & 17.02 & 1 & - & 1 & - \\
\hline & 2012-2017 & 882 & 70.9 & 362 & 29.10 & 0.5 & $<0.0001$ & 0.5 & 0.0002 \\
\hline \multirow[t]{4}{*}{ Age-group } & Sow (Ref.) & 25 & 65.79 & 13 & 34.21 & 1 & - & 1 & - \\
\hline & Piglet & 97 & 69.78 & 42 & 30.22 & 1.20 & 0.637 & 1.00 & 0.999 \\
\hline & Nursery & 557 & 76.72 & 169 & 23.28 & 1.71 & 0.127 & 1.36 & 0.637 \\
\hline & Fattening & 32 & 64 & 18 & 36 & 0.93 & 0.862 & 0.73 & 0.644 \\
\hline \multirow[t]{3}{*}{ Sampling site } & GIT (Ref.) & 1967 & 79.86 & 496 & 20.14 & 1 & - & 1 & - \\
\hline & GUT & 226 & 67.66 & 108 & 32.34 & 0.53 & $<0.0001$ & 0.84 & 0.874 \\
\hline & others & 181 & 73.88 & 64 & 26.12 & 0.71 & 0.028 & 0.96 & 0.796 \\
\hline
\end{tabular}

bias can be ignored in this study. Although E. coli strains analysed in this study were considered to be responsible for the disease picture, a clear microbiological differentiation between commensal and pathogenic $E$. coli strains is not possible [31, 32]. In this study, assessing analysed $E$. coli strains as pathogenic was based on clinical and pathological observations as well as quantification of growth and phenotype of cultured E. coli strains. The E. coli selection and testing procedure was carried out in one accredited laboratory and by only two experienced scientists during the entire study period. This is in contrast to other national and international resistance monitoring programmes collecting preselected isolates from various laboratoriess.

The most important drawback of this study was the lack of meta-data, which mask potential confounding effects. It is known that AMR is influenced by a variety of factors present on farms including endemic infections, cleaning and disinfection protocols, safety requirements for farmers and others [11]. These data cannot be allocated to the respective samples. In this study, comparison of one- and multifactorial regression analysis results revealed these confounding effects by only taking the factors time period, age groups and sampling site into account (Tables 2, 3, 4 and 5). As an example, confounding becomes obvious regarding ampicillin: a simple comparison of the sampling site revealed significant differences in susceptibility of isolates originating from the genito-urinary and the gastrointestinal tract. This effect is diminished when also taking the time period into account in a multifactorial logistic regression model (Table 5). Overall, this problem of residual confounding cannot be eliminated completely in the context of routine data evaluation. In field studies, only a low number of pigs are sampled on one farm and only a small number of bacterial colonies are tested, which might not been representative of the species population on the respective farm [33].

Nevertheless, in spite of the aforementioned drawbacks of this field study, finding significant trends in resistance development from a routine data pool even under these conditions, hints at relevant phenomena of practical impact.

As all MICs have already been determined in routine diagnostics and form the basis for the decision regarding respective antimicrobial substances for animal treatment, our data evaluation was based on the clinical cut-off definition. These clinical break-points are determined by achievable tissue concentrations after treatment with the respective substance $[34,35]$.

Table 5 Ampicillin resistance

\begin{tabular}{|c|c|c|c|c|c|c|c|c|c|}
\hline & & \multicolumn{2}{|c|}{ Resistant isolates } & \multicolumn{2}{|c|}{ Susceptible isolates } & \multicolumn{2}{|c|}{ One-factorial log. Reg. } & \multicolumn{2}{|c|}{ Multi-factorial log. Reg. } \\
\hline & & $\bar{n}$ & $\%$ & $\bar{n}$ & $\%$ & $\overline{\mathrm{OR}}$ & $p$ & $\overline{\mathrm{OR}}$ & $p$ \\
\hline \multirow[t]{2}{*}{ Time period } & 2006-2011 (Ref.) & 1345 & 74.64 & 457 & 25.36 & 1 & - & 1 & - \\
\hline & 2012-2017 & 919 & 73.80 & 325 & 26.13 & 0.96 & 0.634 & 0.64 & 0.014 \\
\hline \multirow[t]{4}{*}{ Age-group } & Sow (Ref.) & 24 & 63.16 & 14 & 36.84 & 1 & - & 1 & - \\
\hline & Piglet & 102 & 72.86 & 38 & 27.14 & 1.57 & 0.246 & 2.46 & 0.173 \\
\hline & Nursery & 578 & 79.5 & 149 & 20.5 & 2.26 & 0.019 & 3.71 & 0.045 \\
\hline & Fattening & 33 & 66.0 & 17 & 34.0 & 1.13 & 0.782 & 1.76 & 0.414 \\
\hline \multirow[t]{3}{*}{ Sampling site } & GIT (Ref.) & 1887 & 76.49 & 580 & 23.51 & 1 & - & 1 & - \\
\hline & GUT & 188 & 56.29 & 146 & 43.71 & 0.40 & $<0.0001$ & 1.98 & 0.332 \\
\hline & others & 189 & 77.14 & 56 & 22.86 & 1.04 & 0.818 & 1.19 & 0.527 \\
\hline
\end{tabular}




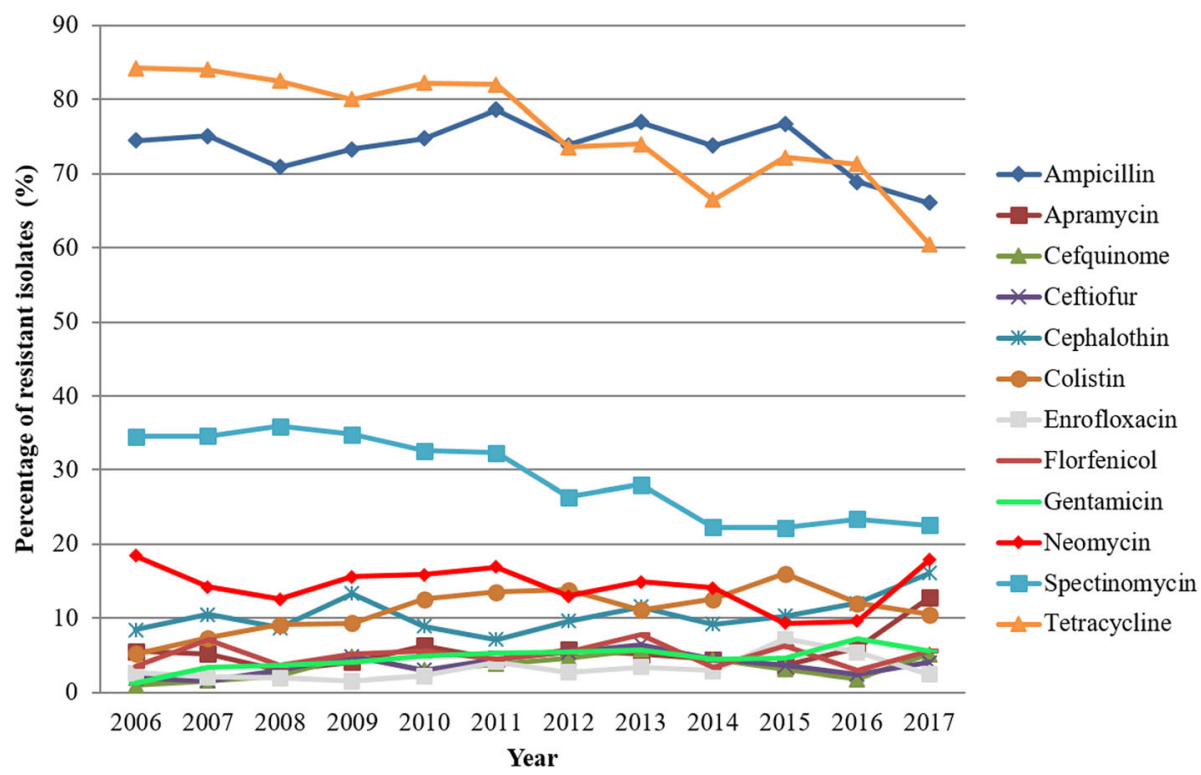

Figure 1 Time dependent development of resistant isolates in the years from 2006 to 2017

Assessing susceptibility of isolates in accordance with epidemiological cut-offs (www.eucast.org, access 8/8/ 2019) resulted in slightly different frequencies of resistant isolates, which were in all cases higher or equal to those assessed by clinical cut-offs (Table 1). This indicates that isolates originate from an artificial environment in domestic pigs exposed to other factors other than wild-type isolates. It must be assumed that they had been targeted by antibiotic treatment. This means that the bacterial population had already undergone a selective pressure.
It was hypothesised that a reduction in antibiotic usage in swine populations in the North Western part of Germany would be reflected by a reduction in frequencies of resistant isolates over time. Multifactorial logistic regression models and analysis of a data subset containing information about organ sampling site and agegroup revealed that only some significant changes in frequencies of resistant isolates can be assigned to the time period. Some findings might reflect the usage of different antimicrobial substances in different age-groups due to the respective dominant disease pictures. This was most

Table 6 Temporal development in AMR for neomycin

\begin{tabular}{|c|c|c|c|c|c|c|c|c|c|c|c|c|c|}
\hline & \multicolumn{7}{|c|}{ Number of isolates with MIC values $(\mathrm{mg} / \mathrm{ml})$ of... } & \multicolumn{2}{|l|}{ S } & \multicolumn{2}{|l|}{ । } & \multicolumn{2}{|l|}{$\mathrm{R}$} \\
\hline & 4 & 16 & 32 & 64 & $\mathrm{n}$ & $\mathrm{MIC}_{50}$ & $\mathrm{MIC}_{90}$ & $n$ & $\%$ & $\mathrm{n}$ & $\%$ & $n$ & $\%$ \\
\hline \multicolumn{14}{|l|}{ Year } \\
\hline 2006 & 242 & 11 & 25 & 32 & 310 & 4.00 & 64.00 & 242 & 78.06 & 11 & 3.55 & 57 & 18.39 \\
\hline 2007 & 319 & 8 & 24 & 30 & 381 & 4.00 & 32.00 & 319 & 83.73 & 8 & 2.10 & 54 & 14.17 \\
\hline 2008 & 266 & 4 & 15 & 24 & 309 & 4.00 & 32.00 & 266 & 86.08 & 4 & 1.29 & 39 & 12.62 \\
\hline 2009 & 227 & 1 & 9 & 33 & 270 & 4.00 & 64.00 & 227 & 84.07 & 1 & 0.37 & 42 & 15.56 \\
\hline 2010 & 224 & 3 & 15 & 28 & 270 & 4.00 & 64.00 & 224 & 82.96 & 3 & 1.11 & 43 & 15.93 \\
\hline 2011 & 218 & 3 & 20 & 25 & 266 & 4.00 & 32.00 & 218 & 81.95 & 3 & 1.13 & 45 & 16.92 \\
\hline 2012 & 227 & . & 2 & 32 & 261 & 4.00 & 64.00 & 227 & 86.97 & . & . & 34 & 13.03 \\
\hline 2013 & 251 & 1 & 13 & 31 & 296 & 4.00 & 64.00 & 251 & 84.80 & 1 & 0.34 & 44 & 14.86 \\
\hline 2014 & 175 & 2 & 9 & 20 & 206 & 4.00 & 32.00 & 175 & 84.95 & 2 & 0.97 & 29 & 14.08 \\
\hline 2015 & 175 & 1 & 3 & 15 & 194 & 4.00 & 4.00 & 175 & 90.21 & 1 & 0.52 & 18 & 9.28 \\
\hline 2016 & 145 & 6 & 3 & 13 & 167 & 4.00 & 16.00 & 145 & 86.83 & 6 & 3.59 & 16 & 9.58 \\
\hline 2017 & 31 & 1 & 3 & 4 & 39 & 4.00 & 64.00 & 31 & 79.49 & 1 & 2.56 & 7 & 17.95 \\
\hline Total & 2500 & 41 & 141 & 287 & 2969 & 4.00 & 32.00 & 2500 & 84.20 & 41 & 1.38 & 428 & 14.42 \\
\hline
\end{tabular}


Table 7 Temporal development in AMR for spectinomycin

\begin{tabular}{|c|c|c|c|c|c|c|c|c|c|c|c|c|c|c|c|}
\hline & \multicolumn{9}{|c|}{ Number of isolates with MIC values $(\mathrm{mg} / \mathrm{ml})$ of... } & \multicolumn{2}{|l|}{ S } & \multicolumn{2}{|l|}{ I } & \multicolumn{2}{|l|}{$\mathrm{R}$} \\
\hline & 4 & 16 & 32 & 64 & 128 & 256 & $\mathrm{n}$ & $\mathrm{MIC}_{50}$ & $\mathrm{MIC}_{90}$ & $n$ & $\%$ & $n$ & $\%$ & $n$ & $\%$ \\
\hline \multicolumn{16}{|l|}{ Year } \\
\hline 2006 & 17 & 94 & 52 & 40 & 32 & 75 & 310 & 32.00 & 256.00 & 163 & 52.58 & 40 & 12.90 & 107 & 34.52 \\
\hline 2007 & 2 & 106 & 87 & 54 & 41 & 91 & 381 & 32.00 & 256.00 & 195 & 51.18 & 54 & 14.17 & 132 & 34.65 \\
\hline 2008 & 3 & 105 & 51 & 39 & 32 & 79 & 309 & 32.00 & 256.00 & 159 & 51.46 & 39 & 12.62 & 111 & 35.92 \\
\hline 2009 & 1 & 81 & 65 & 29 & 25 & 69 & 270 & 32.00 & 256.00 & 147 & 54.44 & 29 & 10.74 & 94 & 34.81 \\
\hline 2010 & . & 79 & 66 & 37 & 20 & 68 & 270 & 32.00 & 256.00 & 145 & 53.70 & 37 & 13.70 & 88 & 32.59 \\
\hline 2011 & 4 & 97 & 53 & 26 & 41 & 45 & 266 & 32.00 & 256.00 & 154 & 57.89 & 26 & 9.77 & 86 & 32.33 \\
\hline 2012 & 3 & 80 & 66 & 43 & 26 & 43 & 261 & 32.00 & 256.00 & 149 & 57.09 & 43 & 16.48 & 69 & 26.44 \\
\hline 2013 & 3 & 120 & 57 & 33 & 32 & 51 & 296 & 32.00 & 256.00 & 180 & 60.81 & 33 & 11.15 & 83 & 28.04 \\
\hline 2014 & 3 & 93 & 47 & 17 & 18 & 28 & 206 & 32.00 & 256.00 & 143 & 69.42 & 17 & 8.25 & 46 & 22.33 \\
\hline 2015 & 12 & 71 & 47 & 21 & 10 & 33 & 194 & 32.00 & 256.00 & 130 & 67.01 & 21 & 10.82 & 43 & 22.16 \\
\hline 2016 & 5 & 72 & 35 & 16 & 15 & 24 & 167 & 32.00 & 256.00 & 112 & 67.07 & 16 & 9.58 & 39 & 23.35 \\
\hline 2017 & & 52 & 31 & 13 & 24 & 4 & 124 & 32.00 & 128.00 & 83 & 66.94 & 13 & 10.48 & 28 & 22.58 \\
\hline Total & 53 & 1050 & 657 & 368 & 316 & 610 & 3054 & 32.00 & 256.00 & 1760 & 57.63 & 368 & 12.05 & 926 & 30.32 \\
\hline
\end{tabular}

obvious when comparing samples from the gastrointestinal and the genitourinary tract. For the substances which are widely used for oral treatment of gastrointestinal tract disorders and have a low tissue penetration, frequencies of resistant isolates were lower in the genitourinary tract. Gastrointestinal disorders in sows are rare and therefore not often targeted by antimicrobial treatment. For enrofloxacin and florfenicol with a high tissue penetration, which are often used in sows for treating bacterial infections of the genito-urinary and respiratory tract, resistant isolates were more frequent [36].
In the resistance monitoring programme GERMAP [24] in pigs with gastrointestinal disorders, frequencies of resistant $E$. coli isolates were comparable to those reported in our study: tetracyclines (69-73\%), ampicillin (67-74\%) and gentamicin (5-12\%). $\mathrm{MIC}_{90}$ of both German sampling pools slightly differed with higher values for apramycin and lower values for enrofloxacin in 2012 in our study compared to the nursery pig evaluation in GERMAP 2015 [24]. In GERMAP, isolates originate from different geographical regions, but are preselected by different laboratories. Meta-data are missing as in most existing national and international monitoring

Table 8 Temporal development in AMR for tetracycline

\begin{tabular}{|c|c|c|c|c|c|c|c|c|c|c|c|c|c|c|c|c|c|}
\hline & \multicolumn{11}{|c|}{ Number of isolates with MIC values $(\mathrm{mg} / \mathrm{ml})$ of... } & \multicolumn{2}{|l|}{ S } & \multicolumn{2}{|l|}{ I } & \multicolumn{2}{|l|}{$\mathrm{R}$} \\
\hline & 0.25 & 0.5 & 1 & 2 & 4 & 8 & 16 & 32 & $n$ & $\mathrm{MIC}_{50}$ & $\mathrm{MIC}_{90}$ & $n$ & $\%$ & $n$ & $\%$ & $n$ & $\%$ \\
\hline \multicolumn{18}{|l|}{ Year } \\
\hline 2006 & . & 26 & & 20 & 2 & 1 & 1 & 260 & 310 & 32.00 & 32.00 & 48 & 15.48 & 1 & 0.32 & 261 & 84.19 \\
\hline 2007 & & 20 & . & 38 & 2 & 1 & . & 320 & 381 & 32.00 & 32.00 & 60 & 15.75 & 1 & 0.26 & 320 & 83.99 \\
\hline 2008 & . & 8 & & 37 & 8 & 1 & 3 & 252 & 309 & 32.00 & 32.00 & 53 & 17.15 & 1 & 0.32 & 255 & 82.52 \\
\hline 2009 & & 3 & . & 43 & 6 & 2 & 2 & 214 & 270 & 32.00 & 32.00 & 52 & 19.26 & 2 & 0.74 & 216 & 80.00 \\
\hline 2010 & . & 5 & . & 35 & 7 & 1 & 2 & 220 & 270 & 32.00 & 32.00 & 47 & 17.41 & 1 & 0.37 & 222 & 82.22 \\
\hline 2011 & & 21 & . & 21 & 4 & 2 & 1 & 217 & 266 & 32.00 & 32.00 & 46 & 17.29 & 2 & 0.75 & 218 & 81.95 \\
\hline 2012 & . & 9 & & 52 & 8 & & & 192 & 261 & 32.00 & 32.00 & 69 & 26.44 & & . & 192 & 73.56 \\
\hline 2013 & . & 18 & . & 53 & 4 & 2 & 2 & 217 & 296 & 32.00 & 32.00 & 75 & 25.34 & 2 & 0.68 & 219 & 73.99 \\
\hline 2014 & 1 & 5 & 17 & 41 & 4 & 1 & & 137 & 206 & 32.00 & 32.00 & 68 & 33.01 & 1 & 0.49 & 137 & 66.50 \\
\hline 2015 & 1 & & 5 & 46 & 1 & 1 & . & 140 & 194 & 32.00 & 32.00 & 53 & 27.32 & 1 & 0.52 & 140 & 72.16 \\
\hline 2016 & & & 7 & 39 & 2 & . & 1 & 118 & 167 & 32.00 & 32.00 & 48 & 28.74 & . & & 119 & 71.26 \\
\hline 2017 & . & & 13 & 36 & & . & 51 & 24 & 124 & 16.00 & 32.00 & 49 & 39.52 & . & . & 75 & 60.48 \\
\hline Total & 2 & 115 & 42 & 461 & 48 & 12 & 63 & 2311 & 3054 & 32.00 & 32.00 & 668 & 21.87 & 12 & 0.39 & 2374 & 77.73 \\
\hline
\end{tabular}


Table 9 Temporal development in AMR for ampicillin

\begin{tabular}{|c|c|c|c|c|c|c|c|c|c|c|c|c|c|c|c|c|c|c|}
\hline & \multicolumn{12}{|c|}{ Number of isolates with MIC values $(\mathrm{mg} / \mathrm{ml})$ of... } & \multicolumn{2}{|l|}{$S$} & \multicolumn{2}{|l|}{ I } & \multicolumn{2}{|l|}{$\mathrm{R}$} \\
\hline & 0.25 & 0.5 & 1 & 2 & 4 & 8 & 16 & 32 & 64 & $\mathrm{n}$ & $\mathrm{MIC}_{50}$ & $\mathrm{MIC}_{90}$ & $n$ & $\%$ & $n$ & $\%$ & $n$ & $\%$ \\
\hline \multicolumn{19}{|l|}{ Year } \\
\hline 2006 & & 2 & 15 & 46 & 13 & 2 & 1 & 1 & 230 & 310 & 64 & 64 & 78 & 25.16 & 1 & 0.32 & 231 & 74.52 \\
\hline 2007 & . & . & 7 & 55 & 29 & 4 & . & 4 & 282 & 381 & 64 & 64 & 95 & 24.93 & . & . & 286 & 75.07 \\
\hline 2008 & & . & 2 & 50 & 30 & 7 & 1 & . & 219 & 309 & 64 & 64 & 89 & 28.80 & 1 & 0.32 & 219 & 70.87 \\
\hline 2009 & . & & 4 & 28 & 33 & 6 & 1 & 1 & 197 & 270 & 64 & 64 & 71 & 26.30 & 1 & 0.37 & 198 & 73.33 \\
\hline 2010 & . & & 5 & 32 & 30 & 1 & . & 1 & 201 & 270 & 64 & 64 & 68 & 25.19 & . & . & 202 & 74.81 \\
\hline 2011 & . & . & 10 & 33 & 13 & . & 1 & . & 209 & 266 & 64 & 64 & 56 & 21.05 & 1 & 0.38 & 209 & 78.57 \\
\hline 2012 & . & & 1 & 35 & 27 & 4 & 1 & 2 & 191 & 261 & 64 & 64 & 67 & 25.67 & 1 & 0.38 & 193 & 73.95 \\
\hline 2013 & & . & 2 & 19 & 42 & 5 & . & 1 & 227 & 296 & 64 & 64 & 68 & 22.97 & $\cdot$ & . & 228 & 77.03 \\
\hline 2014 & 1 & & 4 & 23 & 22 & 3 & 1 & 3 & 149 & 206 & 64 & 64 & 53 & 25.73 & 1 & 0.49 & 152 & 73.79 \\
\hline 2015 & . & . & 1 & 17 & 24 & 2 & 1 & . & 149 & 194 & 64 & 64 & 44 & 22.68 & 1 & 0.52 & 149 & 76.80 \\
\hline 2016 & . & & 2 & 27 & 19 & 3 & 1 & 1 & 114 & 167 & 64 & 64 & 51 & 30.54 & 1 & 0.60 & 115 & 68.86 \\
\hline 2017 & . & . & . & 25 & 16 & 1 & . & 1 & 81 & 124 & 64 & 64 & 42 & 33.87 & . & . & 82 & 66.13 \\
\hline Total & 1 & 2 & 53 & 390 & 298 & 38 & 8 & 15 & 2249 & 3054 & 64 & 64 & 782 & 25.61 & 8 & 0.26 & 2264 & 74.13 \\
\hline
\end{tabular}

programmes. In spite of these restrictions, it has to be taken into account that differences in frequencies of resistant isolates between different studies are partly due to these methodological differences and therefore have to be interpreted with caution [37].

According to literature studies, our data differ to other regions of the world. In a study in 2018 on commensal $E$. coli isolates from healthy slaughter pigs in Australia, frequencies of resistant isolates (ampicillin $\sim 60.2 \%$, tetracycline $68.2 \%$, ciprofloxacin $1 \%$, gentamicin and ceftiofur $0 \%$ ) were lower than in our German sampling [38], which is mainly due to the fact that only healthy slaughter pigs were sampled in this previous study. A recent study in Estonia revealed lower percentages of tetracyclineresistant $E$. coli isolates in healthy swine (32.5\%) compared to diseased swine (60.2\%) as well [39]. The comparison of haemolytic $E$. coli pathotypes isolated from diarrhoeic piglets in the USA revealed marked differences in susceptibility between ETEC and non-ETEC with respect to enrofloxacin (58.2\% vs. $5.0 \%)$ and gentamicin $(32.7 \%$ vs. $7.5 \%)$ [40]. Overall, strains were highly resistant to oxytetracycline (91.6\%) and ampicillin (75.8\%) in this study.

Although in our study no simultaneous data on respective farms for AMU and AMR were evaluated, diagnostic findings in most swine dense regions in Germany might reflect the effects of efforts to reduce antibacterial resistances. In general, low frequencies with less than $15 \%$ of resistant isolates were found for colistin, neomycin, cefquinome, ceftiofur, cephalothin, gentamicin, enrofloxacin, florfenicol and apramycin, while higher frequencies were found for ampicillin, tetracycline and spectinomycin. The time-dependent analysis of antimicrobial resistances in $E$. coli reported in this study resulted in a significant decrease in the frequency of isolates resistant to tetracycline to the aminoglycosid antibiotics neomycin and spectinomycin in the multivariate logistic regression model. These decreases are paralleled by a decrease in sales data for these substances in Germany since 2012 [41] as well as by a reduction in antibiotic usage in livestock since 2011, which was paralleled by monitoring projects and the implementation of the Second Version of Guidelines on the Prudent Use of Veterinary Antimicrobial Drugs presented by the Federal Veterinary Surgeons' Association [21, 22, 42]. This corresponded to the reduction in the number of administered daily doses in the same observation period. Significant changes in treatment frequencies were already recorded as results within the German VetCab project from the first half of 2011 to the second half of 2014 in piglets (decrease from 3.8 to 1.7) and fattening pigs (5.1-0.7), while treatment frequency in weaners was highly variable and in sows remained constantly low [21]. Since the start of antibiotic usage records which have been required 2014, the median treatment frequency for weaners has been reduced from 4.79 to 3.02 and for fatteners from 1.19 to 0.3 [23, 43, 44]. Efforts to reduce antibiotic usage in livestock at working levels were accompanied by a radical strengthening of the veterinary control stipulated in the German Pharmaceutical Act in 2014 [25]. Treatment frequencies with respect to particular antibiotic substances reported in VetCab [22], but also continuously in the German Quality assurance database (www. q-s.de/softwareplattform/en/, access 10/ $11 / 2019)$ show similar trends as the sales data for antibiotics drugs. The highest reduction rate in sales data from 2011 to 2017 was achieved for tetracyclines by more 
than $66 \%$. Aminoglycosid antibiotics were reduced by more than $37 \%$ in the same time-period [16]. In contrast to that, sales data of fluorchinolones belonging to the Highest Priority Critically Important Antimicrobials varied between the years, so that in fact. no reduction was achieved. This might be reflected by an age-group related increase in the percentage of enrofloxacin-resistant isolates in sows. Nevertheless, the fact that samples from the genito-urinary tract from sows nearly halved in the timeperiod 2012-2017 might be due to a better health status of sows by improved vaccination and gilt acclimatisation protocols. In addition, higher numbers of piglets born alive due to advanced breeding resulting in a higher reproductive performance of sows, has demanded excellent management in the recent years. Increased standards in pig production require more specialised farmers who are able to perpetuate a high health status in their herd. The generally higher health status in sows might be reflected by less sampling and an age- and time-dependent reduction in ampicillin-resistant isolates. This development is in parallel to a reduction in sales data for penicillins by $49 \%$ in the same time period [16]. Alternatively individual parenteral treatment of sows with fluorchinolones might be chosen as a treatment strategy by farmers.

In general, the relationship between antibiotic treatment and occurrence of resistant isolates has been shown in livestock animals [45]. Recently, a positive relationship between oral administration of chlortetracycline in nursery pigs and the probability of occurrence of $E$. coli isolates resistant to chlortetracycline and ceftiofur has been described [46]. In Australia, the very low level of non-susceptibility to critically important antimicrobials such as thirdgeneration cephalosporins and fluoroquinolones in healthy slaughter pigs might be attributed to the fact that fluoroquinolones are not legally available for food-producing animals in this continent [38]. In 2006/2007, a limited number of $43 \mathrm{E}$. coli isolates also from healthy swine in Argentina were examined for minimal inhibitory concentration distribution [47]. The authors attributed the levels of non-susceptible isolates to those drugs used most commonly in pig production (ampicillin 77\%, tetracycline $88 \%$, florfenicol $98 \%$, gentamicin $5 \%$, enrofloxacin 2\%) [47].

A literature systematic review based on thirteen relevant articles revealed a relationship between AMR pattern in herds and dosage, route of administration and frequency of AMU. Several additional factors had a statistically significant influence on AMR on herd level, as space allowance, cleanliness, time span between sampling and treatment and distance to another farm [48]. Higher odds ratios were found for resistance of $E$. coli to quinolones, aminoglycosides and tetracycline in herds with oral administration of antimicrobials [7]. All published studies linking AMU to AMR revealed that research must focus on the effects of specific management practices more than only on AMU. Understanding resistance mechanisms, their distribution among bacterial populations and environmental factors triggering their occurrence are indispensable. Not only antimicrobial substances produce a selective pressure towards a more resistant bacterial community, but also several other substances which are present in a farm environment. Naturally occurring antimicrobial substances can be produced by bacterial species, especially in a tight bacterial community as in biofilms, e.g. in slurry, water or feeding pipes. At these localisations, a high density of bacterial cells enables horizontal gene transfer as an additional factor for the spread of resistant bacteria in the environment [49].

A general bacterial stress response or expression of multi-drug resistance pumps following exposure to disinfectants, can also trigger development of resistance to antimicrobials [50]. This effect was also found after bacterial exposure to specific nutritional elements in feed, e.g. zinc and copper [51]. Zinc is used in high concentrations $(1000-3000 \mathrm{ppm})$ for treating diarrohea or enterotoxaemia caused by pathogenic $E$. coli in nursery pigs [52].

In general, to link antibiotic usage to resistance development at farm level, fundamental data are necessary, which are lacking in this study. Antibiotic consumption data have to be recorded at farm level, including name and galenic product, number of treated animals, indication and dosage [24]. Sample size and sampling sites for susceptibility testing in an adequate number of isolates should be determined following statistical recommendations. For future analyses, if efforts to reduce antibiotic usage are effective to reduce resistant bacterial isolates, the evaluation of more epidemiological data as well as case-control studies are necessary. The present study can be considered as a first step in analysing trends in resistance development in the region with highest pig density and highest consumption of antimicrobial substances in livestock animals in Germany.

\section{Conclusion}

E.coli is a well accepted sentinel for antimicrobial resistance monitoring in livestock. In a North Western part of Germany, the effects of age-group, organ sampling sites and the time-period on the frequency of antimicrobial resistances were found within the years 2011 to 2017. The percentage of tetracycline-, spectinomycin- and neomycin-resistant isolates decreased significantly in a time-dependent manner. This 
observation is in parallel with a reduction in usage of these antibiotic substances in Germany. In summary, the efficiency of antibiotic drugs for the future can be preserved if prescription and usage of antimicrobial substances are further controlled and monitored in human and veterinary medicine and are in part replaced by alternative treatment approaches. Simultaneously, monitoring of bacterial resistances in combination with recording of data on exposure of the respective strains to factors triggering development of antimicrobial resistance will pave the way for new strategies to decrease the development of antibacterial resistance.

\section{Methods}

\section{Sample collection, isolation of bacterial strains and susceptibility testing}

From 1 January 2006 to 31 December 2017, MIC values from $3054 \mathrm{E}$. coli isolates from diseased pigs sent for routine diagnostics or sampled on-farm were evaluated. Within 1 year, only the first E. coli isolate from a respective farm was included in the data set. The majority of isolates originated from different organs of diseased swine, which had been necropsied for diagnostic reasons. All other isolates originated from samples which had been taken by veterinarians from diseased animals on swine farms and sent for diagnostics. In total, isolates originated from 2161 farms in a swine dense region in North Western Germany. The majority, that of $95.8 \%$ of the farms, were located in three neighbouring zones. Identification numbers were allocated to individual samples and the information related to the sample, as origin, sampling site, date of sampling, the bacteria isolated and their MIC as well as qualitative assessment of resistance. In a subset of data, also information about the age group was available $(n=956)$. Distribution of sampling sites among the age groups is shown in Table 10.

E. coli was identified by standard bacteriological cultivation and biochemical tests. In total, 39\% (1192) of the E. coli strains were isolated from the jejunum, 32.7\% (998) from faeces and 9.3\% (283) from the mesenteric lymph nodes. Eleven \% (336) of isolates originated from the genito-urinary tract and 8\% (245) from other organs.

Isolates from sows (4\%) originated mainly from the genito-urinary tract (79\%). The highest percentage of isolates was collected from nursery pigs (76.1\%), followed by suckling piglets (14.6\%) and fatteners $(5.2 \%)$. In these age-groups, most isolates were from the gastro-intestinal tract (suckling piglets: $61 \%$, nursery piglets: $96 \%$, fatteners $84 \%$ ). No commensal E. coli were included in the evaluation. Pathogenic potential of isolates was assessed by clinical and pathomorphological findings, the quantity of growth in primary culture and the phenotype of the colonies.

\section{Antimicrobial susceptibility testing}

Seventeen antimicrobial agents of different concentrations were included in antimicrobial susceptibility testing of bacterial strains following the recent CLSI manuals [53, 54] in a commercial microtiter plate assay (Sensititre ${ }^{\circ}$ NLV 39, TREK Diagnostic Systems Ltd., Cleveland, USA) with a standardised layout for livestock animals [55]: ampicillin $(0.12-32 \mu \mathrm{g} / \mathrm{mL})$, apramycin $(8-32 \mu \mathrm{g} / \mathrm{mL})$, ceftiofur $(0.12-8 \mu \mathrm{g} / \mathrm{mL})$, cefquinome $(1-8 \mu \mathrm{g} / \mathrm{mL})$, cephalothin $(1-16 \mu \mathrm{g} / \mathrm{mL})$, clindamycin $(0.25-4 \mu \mathrm{g} / \mathrm{mL})$, colistin $(0.5-4 \mu \mathrm{g} / \mathrm{mL})$, erythromycin $(0.12-4 \mu \mathrm{g} / \mathrm{mL})$, enrofloxacin $(0.03-2 \mu \mathrm{g} / \mathrm{mL})$, florfenicol $(1-8 \mu \mathrm{g} / \mathrm{mL})$, gentamicin $(0.25-8 \mu \mathrm{g} / \mathrm{mL})$, neomycin $(8-32 \mu \mathrm{g} / \mathrm{mL})$, penicillin $G$ $(0.06-16 \mu \mathrm{g} / \mathrm{mL})$, spectinomycin $(4-64 \mu \mathrm{g} / \mathrm{mL})$, tetracycline $(0.12-8 \mu \mathrm{g} / \mathrm{mL})$, tiamulin $(8-32 \mu \mathrm{g} / \mathrm{mL})$, tilmicosin $(1-32 \mu \mathrm{g} / \mathrm{mL})$. Data for penicillin G, erythromycin, clindamycin, tiamulin and tilmicosin were not included in the evaluation for its natural resistance to these substances.

The E. coli reference strain ATCC 25922 was used as control strain. Colony material of the respective isolate was suspended in $5 \mathrm{~mL} \mathrm{NaCl}$ and optical density was adjusted to 0.5 in Mc Farland broth (Becton, Dickinson and Company, Maryland, USA) measured in a densitometer (bioMérieux Marcy l'Etoile, Marcy l'Etoile, France). Optical density of 0.5 corresponds to $10^{6}-10^{8} \mathrm{CFU} / \mathrm{mL}$. Ten microliter of the suspension was mixed with $10 \mathrm{~mL}$

Table 10 Distribution of E. coli isolates originating from different sampling sites and age groups

\begin{tabular}{|c|c|c|c|c|c|c|c|c|c|c|}
\hline \multirow[t]{2}{*}{ Sampling site } & \multicolumn{2}{|c|}{ Suckling piglets } & \multicolumn{2}{|c|}{ Nursery pigs } & \multicolumn{2}{|c|}{ Fatteners } & \multicolumn{2}{|c|}{ Sows } & \multicolumn{2}{|c|}{ All samples ${ }^{a}$} \\
\hline & $n$ & $\%$ & $\mathrm{n}$ & $\%$ & $\mathrm{n}$ & $\%$ & $\mathrm{n}$ & $\%$ & $\mathrm{n}$ & $\%$ \\
\hline Jejunum & 64 & 45.7 & 511 & 70.2 & 30 & 60.0 & 3 & 7.9 & 1192 & 39.0 \\
\hline Feces & 1 & 0.7 & 0 & 0 & 1 & 2.0 & 0 & 0 & 998 & 32.7 \\
\hline Mesenteric lymph nodes & 20 & 14.3 & 184 & 25.3 & 11 & 22.0 & 0 & 0 & 283 & 9.3 \\
\hline Genito-urinary tract & 1 & 0.7 & 1 & 0.1 & 2 & 4.0 & 30 & 78.9 & 336 & 11.0 \\
\hline Other organs & 54 & 38.6 & 32 & 4.4 & 6 & 12.0 & 5 & 13.2 & 245 & 8.0 \\
\hline Total & 140 & 100 & 728 & 100 & 50 & 100 & 38 & 100 & 3054 & 100 \\
\hline
\end{tabular}

${ }_{\text {including samples from pigs without information about age-group }}$ 
of sterile Müller-Hinton-Bouillon and $50 \mu \mathrm{L}$ of the inoculum were transferred to each well of a commercially available microtiter plate (Sensititre ${ }^{\bullet}$ NLV 39, TREK Diagnostic Systems Ltd., Cleveland, USA). Different wells were coated with different concentrations of antimicrobial substances in two-fold dilutions in a range overlapping MICs reflecting resistance and intermediate susceptibility in accordance with the cut-off of the test organism as well as the Clinical and Laboratory Standards Institute (CLSI) cut-offs. The microtiter plate was incubated at $36^{\circ} \mathrm{C} \pm 1{ }^{\circ} \mathrm{C}$ for $18-24 \mathrm{~h}$. Results were electronically recorded and printed out with the Sensitouch device (Sensititre, Cleveland, USA). Susceptibility and resistance of bacterial isolates were assessed with respect to clinical breakpoints of the CLSI guidelines [53, 56]. Bacterial isolates were categorised as "susceptible" (s), "intermediate" (i) or "resistant" (r). During the evaluation period 20062017, all testings were performed by the same two experienced persons in the same accredited laboratory following the respective Standard Operating Procedures. For the years evaluated, always the same cut-offs were used for assessing the resistance patterns. If no clinical cut-offs were available, other published cut-offs were used. For ampicillin, cephalothin, gentamicin and tetracycline, neither animalspecific nor pathogen-specific cut-offs were available. Therefore, the cut-offs for $E$. coli isolates from human were used. Cut-offs were as follows (susceptible/ intermediate/ resistant, concentrations in $\mu \mathrm{g} /$ $\mathrm{mL}$ ): ampicillin: $\leq 8 / 16 / \geq 32$ [57]; cephalothin: $\leq 8$ / 16 / $\geq 32$ [56]; gentamicin: $\leq 4 / 8 / \geq 16$ [57] and tetracycline: $\leq 4 / 8 / \geq 16$ [57]. The MICs for ceftiofur $(\leq 2 / 4 / \geq 8)$ [57], enrofloxacin $(\leq 0.25 / 0.5-1 /$ $\geq 2)$ [57], florfenicol $(\leq 2 / 4 / \geq 8)$ [53] and spectinomycin $(\leq 32$ / $64 / \geq 128)$ [53] were validated for animals. The MICs for apramycin $(\leq 16 /-/ \geq 32)$, cefquinome $(\leq 2 / 4 / \geq 8)$, colistin $(\leq 0.5 / 1-2 / \geq 4)$ and neomycin $(\leq 8 / 16 / \geq 32)$ were based on DIN 58940 for humans [58]. For assessing an epidemiological impact of strains originating from diseased animals, an additional evaluation was performed based on available current epidemiological cut-offs for E. coli [59]. The cut-offs are shown in Table 11.

Clinical and epidemiological cut-offs used in this study for assessing MIC in E. coli isolates from diseased pigs. Epidemiological cut-off $(\mu \mathrm{g} / \mathrm{mL})$ : European Committee on Antimicrobial Susceptibility Testing. Data from the EUCAST MIC distribution website, last accessed 05.08.2019, http://www.eucast.org).

\section{Data management}

All data were registered by means of the laboratory information system LabControl, Version 2002, Ticono-Software, Hannover and exported to Excel, Version 2010 (Microsoft Corporation, Albuquerque, USA). Statistical analyses were performed via SAS, version 9.4 (SAS Institute, NC, USA).

Different sampling site descriptions existing in the database were summarised to three localisations as the gastrointestinal tract containing jejunum, faeces and mesenteric lymph nodes, genito-urinary tract and other organs (Table 10).

MIC distributions of each antimicrobial agent were visualised using bar graphs showing the relative frequencies of susceptible, intermediate and resistant isolates. $\mathrm{MIC}_{50}$ and $\mathrm{MIC}_{90}$-values were calculated, corresponding to the median and the 90\%-quantile of the sampling pool, respectively [60]. Isolates were categorised as "susceptible" and "resistant". To address the hypothesis of an impact of reduction in AMU and stricter legislation since 2011 with respect to prescription of antimicrobials

Table 11 Clinical and epidemiological cut-offs

\begin{tabular}{llll}
\hline & Clinical cut-off $(\mu \mathrm{g} / \mathrm{mL}) \leq$ & Reference for clinical cut-off & Epidemiological cut-off $(\mu \mathrm{g} / \mathrm{mL}) \leq$ \\
\hline Ampicillin & 8 & Human [57] & 8 \\
Apramycin & 16 & Human [58] & 1 \\
Ceftiofur & 2 & Animal [57] & \\
Cefquinome & 2 & Human [58] & 32 \\
Cephalothin & 8 & Human [56] & 2 \\
Colistin & 0.5 & Human [58] & 0.125 \\
Enrofloxacin & 0.25 & Animal [57] & 16 \\
Florfenicol & 2 & Animal [53] & 2 \\
Gentamicin & 4 & Human [57] & 8 \\
Neomycin & 8 & Human [58] & 64 \\
Spectinomycin & 32 & Animal [53] & 8 \\
Tetracycline & 4 & Human [57] & 8 \\
\hline
\end{tabular}


on frequencies of resistant isolates, the final evaluation of data was performed by a comparison of the two time periods 2006-2011 and 2012-2017. Frequencies were compared by means of the chisquare test and logistic regression models.

To visualise the temporal AMR development per antimicrobial agent, graphs were generated showing the relative percentage of resistant isolates over time (Fig. 1).

The chi-square test was used for the comparing AMR frequencies from different sampling sites, age-groups and time-periods. Subsequently, simple logistic regression models were calculated to further identify major differences between groups. Finally, a multifactorial logistic regression model was performed to analyse the impact of age-group and sampling site on temporal changes in frequencies of resistant isolates. The level of significance for all statistical models was set at 0.05 without any adjustment for multiple testing.

\section{Supplementary information}

Supplementary information accompanies this paper at https://doi.org/10. 1186/s12917-020-2268-z.

Additional file 1. Multifactorial logistic regression analysis with fixed effect time period and factors "age-group" and "sampling site" with respect to apramycin resistance (1a), cefquinome resistance (1b), ceftiofur resistance $(1 \mathrm{c})$, cephalothin resistance $(1 \mathrm{~d})$, colistin resistance (1e), enrofloxacin resistance $(1 \mathrm{f})$, florfenicol resistance $(1 \mathrm{~g})$ and gentamicin resistance (1 h).

Additional file 2. Temporal development in AMR for apramycin (1a), cefquinome (1b), ceftiofur (1c), cephalothin (1d), colistin (1e), enrofloxacin (1f), florfenicol (1 g) and gentamicin (1 h).

\section{Abbreviations}

AMR: Antimicrobial resistance; AMU: Antimicrobial use; ATCC: American Type Culture Collection; CFU/mL: Colony-forming unit per millilitre; CLSI: Clinical and Laboratory Standards Institute; DIMDI-Ordinance: Ordinance on the Database-supported Information System on Medical Devices of the German Institute for Medical Documentation and Information; DNA: Deoxyribonucleic acid; E. coli: Escherichia coli; e.g.: exempli gratia; EARSS: European Antimicrobial Resistance Surveillance System; ETEC: Enterotoxic Escherichia coli; GERMAP: German Programme for surveillance of antimicrobial consumption and resistance in bacteria; GIT: Gastrointestinal tract; GLASS: Global Antimicrobial Resistance Surveillance System; GUT: Genitourinary tract; i: intermediate; mg/L: milligramme per litre; mg/ $\mathrm{mL}$ : milligramme per millilitre; mg/PCU: milligramme per Population Correction Units; MIC: Minimal inhibitory concentration; $\mathrm{mL}$ : millilitre; n: number; $\mathrm{NaCl}$ : Sodium chloride; OlE: Office International des Epizooties; ppm: parts per million; R [\%]: Relative frequency; r: resistant; s: susceptible; WHO: World Health Organization; $\mu \mathrm{g} / \mathrm{kg}$ : Microgramme per kilogramme; $\mu \mathrm{g} /$ $\mathrm{mL}$ : Microgramme per millilitre; $\mu \mathrm{L}$ : Microlitre

\section{Acknowledgements}

The authors gratefully acknowledge the support from the team at the Field Station for Epidemiology in Bakum, University of Veterinary Medicine Hannover, Germany for collecting the data.

\section{Authors' contributions}

IHP designed the study. FN and HD collected and exported the data from the laboratory information system. CM, NT, MH, AM, LK, JM and IHP participated in the data analysis. CM interpreted the data and wrote the paper. IHP and LK reviewed the manuscript. All authors read and approved the final manuscript.
Funding

Not applicable.

\section{Availability of data and materials}

The datasets used and/or analysed during the current study are available from the corresponding author on reasonable request.

Ethics approval and consent to participate

Not applicable.

\section{Consent for publication}

Not applicable.

\section{Competing interests}

The authors declare that they have no competing interests.

\section{Author details}

${ }^{1}$ Field Station for Epidemiology in Bakum, University of Veterinary Medicine Hannover, Hanover, Germany. ${ }^{2}$ Department of Biometry, Epidemiology and Information Processing, WHO Collaborating Centre for Research and Training for Health at the Human-Animal-Environment Interface, University of Veterinary Medicine Hannover, Hanover, Germany. ${ }^{3}$ Department of Infectious Diseases, Institute for Microbiology, University of Veterinary Medicine Hannover, Hanover, Germany.

Received: 29 March 2019 Accepted: 27 January 2020

Published online: 03 February 2020

\section{References}

1. Levy SB, Marshall B. Antibacterial resistance worldwide: causes, challenges and responses. Nature Med. 2004;10:122-9.

2. Roca I, Akova M, Baquero F, Carlet J, Cavaleri M, Coenen S, et al. The global threat of antimicrobial resistance: science for intervention. New Microbes New Infect. 2015;6:22-9.

3. Megraud F, Coenen S, Versporten A, Kist M, Lopez-Brea M, Hirschl AM, et al. Helicobacter pylori resistance to antibiotics in Europe and its relationship to antibiotic consumption. Gut. 2013;62:34-42.

4. Bronzwaer SL, Cars O, Buchholz U, Mölstad S, Goettsch W, Veldhuijzen IK, et al. The relationship between antimicrobial use and antimicrobial resistance in Europe. Emerg Infect Dis. 2002;8:278-82.

5. Valentin L, Sharp H, Hille K, Seibt U, Fischer J, Pfeifer Y, et al. Subgrouping of ESBL-producing Escherichia coli from animal and human sources: an approach to quantify the distribution of ESBL types between different reservoirs. Int J Med Microbiol. 2014;304:805-16.

6. Burow E, Rostalski A, Harlizius J, Gangl A, Simoneit C, Grobbel M, et al. Antibiotic resistance in Escherichia coli from pigs from birth to slaughter and its association with antibiotic treatment. Prev Vet Med. 2019;165:52-62.

7. Burow E, Simoneit C, Tenhagen B-A, Käsbohrer A. Oral antimicrobials increase antimicrobial resistance in porcine E. coli-a systematic review. Prev Vet Med. 2014;113:364-75.

8. Callens B, Cargnel M, Sarrazin S, Dewulf J, Hoet B, Vermeersch K, et al. Associations between a decreased veterinary antimicrobial use and resistance in commensal Escherichia coli from Belgian livestock species (2011-2015). Prev Vet Med. 2018;157:50-8.

9. Græsbøll K, Damborg P, Mellerup A, Herrero-Fresno A, Larsen I, Holm A, et al. Effect of tetracycline dose and treatment mode on selection of resistant coliform bacteria in nursery pigs. Appl Environ Microbiol. 2017:83:1-12

10. Ghanbari M, Klose V, Crispie F, Cotter PD. The dynamics of the antibiotic resistome in the feces of freshly weaned pigs following therapeutic administration of oxytetracycline. Sci Rep. 2019;9:1-11.

11. Murphy CP, Carson C, Smith BA, Chapman B, Marrotte J, McCann M, et al. Factors potentially linked with the occurrence of antimicrobial resistance in selected bacteria from cattle, chickens and pigs: a scoping review of publications for use in modelling of antimicrobial resistance (IAM. AMR project). Zoonoses Public Health. 2018;65:957-71.

12. Van Gompel L, Luiken RE, Sarrazin S, Munk P, Knudsen BE, Hansen RB, et al. The antimicrobial resistome in relation to antimicrobial use and biosecurity in pig farming, a metagenome-wide association study in nine European countries. J Antimicrob Chemother. 2019;74:865-76.

13. Randall L, Horton R, Lemma F, Martelli F, Duggett N, Smith R, et al. Longitudinal study on the occurrence in pigs of colistin-resistant Escherichia 
coli carrying mcr-1 following the cessation of use of colistin. J Appl Microbiol. 2018;125:596-608.

14. Sarrazin S, Joosten P, Van Gompel L, Luiken RE, Mevius DJ, Wagenaar JA, et al. Quantitative and qualitative analysis of antimicrobial usage patterns in 180 selected farrow-to-finish pig farms from nine European countries based on single batch and purchase data. J Antimicrob Chemother. 2018;74:807-16.

15. Anthony F, Acar J, Franklin A, Gupta R, Nicholls T, Tamura Y, et al. Antimicrobial resistance: responsible and prudent use of antimicrobial agents in veterinary medicine. Rev Sci Tech. 2001;20:829-37.

16. Wallmann J, Bode C, Bender A, Heberer T. Abgabemengenerfassung von Antibiotika in Deutschland 2017. DTBI. 2018:66:1238-47.

17. Kresken M, Wallmann J, Kem W. GERMAP 2008. Antibiotika-Resistenz und -Verbrauch. Bericht über den Antibiotikaverbrauch und die Verbreitung von Resistenzen in der Human und Veterinämedizin in Deutschland. Rheinbach: Antiinfectives Intelligence; 2008.

18. Pabel HJ. Arzneimittelgesetz: in der Fassung der Bekanntmachung vom 12. Dezember 2005 (BGBI. I S. 3394), das durch Artikel 2 G v. der Verordnung vom 19. Oktober 2012 geändert worden ist (BGBI. I S. 2192): Dt. Apotheker-Verlag; 2006.

19. Bundesministerium für Ernährung LuV. Verordnung über das datenbankgestützte Informationssystem über Arzneimittel des Deutschen Instituts für Medizinische Dokumentation und Information (DIMDIArzneimittelverordnung - DIMDI-AMV [DIMDI-AMV]; 2010. p. 140.

20. van Rennings $L$, von Münchhausen $C$, Ottilie $H$, Hartmann $M$, Merle $R$, Honscha W, et al. Cross-sectional study on antibiotic usage in pigs in Germany. PLoS One. 2015;10:1-28.

21. Hemme M, Ruddat I, Hartmann M, Werner N, van Rennings L, Käsbohrer A, et al. Antibiotic use on German pig farms-a longitudinal analysis for 2011, 2013 and 2014. PLoS One. 2018;13:1-17.

22. Schaekel F, May T, Seiler J, Hartmann M, Kreienbrock L. Antibiotic drug usage in pigs in Germany —are the class profiles changing? PLoS One. 2017;12:1-15.

23. Rahbauer M. Vergleich unterschiedlicher Berechnungsmodelle zum Monitoring von Antibiotika-Verbrauchsmengen, sowie Überprüfung des Einflusses betriebsspezifischer Parameter auf den Therapieindex, die Animal Daily Dose und die Netherlands Animal Daily Dose in süddeutschen Schweinemastbetrieben; Dissertation, Tierärztliche Fakultät der LudwigMaximilian-Universität München 2015.

24. Kresken M, Wallmann J, Kern W. GERMAP 2015. Antibiotika-Resistenz und Verbrauch. Bericht über den Antibiotikaverbrauch und die Verbreitung von Antibiotikaresistenzen in der Human-und Veterinärmedizin in Deutschland. Rheinbach: Antiinfectives Intelligence; 2017.

25. Ferreira JP, Staerk K Antimicrobial resistance and antimicrobial use animal monitoring policies in Europe: where are we? J Public Health Policy. 2017;38:185-202.

26. Wiedemann B. Mechanismen und Epidemiologie der Antibiotikaresistenz. Internist. 2000:41:1205-11.

27. Tenover FC. Mechanisms of antimicrobial resistance in bacteria. Am J Med. 2006;119:3-10

28. Santajit $\mathrm{S}$, Indrawattana N. Mechanisms of antimicrobial resistance in ESKAPE pathogens. Biomed Res Int. 2016;2016:2475067.

29. Wallmann J. Monitoring of antimicrobial resistance in pathogenic bacteria from livestock animals. Int J Med Microbiol. 2006;296:81-6.

30. World Health Organization. Integrated Surveillance of Antimicrobial Resistance in Foodborne Bacteria: Application of a One Health Approach. 2017; Licence: CC BY-NC-SA 3.0 IGO

31. Chapman TA, Wu X-Y, Barchia I, Bettelheim KA, Driesen S, Trott D, et al. Comparison of virulence gene profiles of Escherichia coli strains isolated from healthy and diarrheic swine. Appl Environ Microbiol. 2006;72:4782-95.

32. Luppi A. Swine enteric colibacillosis: diagnosis, therapy and antimicrobial resistance. PHM. 2017:3:1-18.

33. Ström G, Halje M, Karlsson D, Jiwakanon J, Pringle M, Fernström L-L, et al. Antimicrobial use and antimicrobial susceptibility in Escherichia coli on smalland medium-scale pig farms in North-Eastern Thailand. ARIC. 2017;6:1-9.

34. Silley $P$, de Jong $A$, Simjee $S$, Thomas $V$. Harmonisation of resistance monitoring programmes in veterinary medicine: an urgent need in the EU? Int J Antimicrob Agents. 2011;37:504-12.

35. Bywater R, Silley P, Simjee S. Antimicrobial breakpoints-definitions and conflicting requirements. Vet Microbiol. 2006;1 18:158-9.

36. Federal Veterinary Surgeons' Association. Guidelines for the prudent use of veterinary antimicrobial drugs - with notes for guidiance. Addendum to the German Veterniary Gazette 3/2015; 2015. p. 1-24.

37. Schwarz S, Silley P, Simjee S, Woodford N, van Duijkeren E, Johnson AP, et al. Assessing the antimicrobial susceptibility of bacteria obtained from animals. J Antimicrob Chemother. 2010;65:601-4.
38. Kidsley AK, Abraham S, Bell JM, O'Dea M, Laird TJ, Jordan D, et al. Antimicrobial susceptibility of Escherichia coli and Salmonella spp. isolates from healthy pigs in Australia: results of a pilot national survey. Front Microbiol. 2018;9:1-12.

39. Aasmäe B, Häkkinen L, Kaart T, Kalmus P. Antimicrobial resistance of Escherichia coli and Enterococcus spp. isolated from Estonian cattle and swine from 2010 to 2015. AVS. 2019:61:1-8.

40. Jiang F, Wu Z, Zheng Y, Frana TS, Sahin O, Zhang Q, et al. Genotypes and antimicrobial susceptibility profiles of hemolytic Escherichia coli from diarrheic piglets. Foodborne Pathog Dis. 2019;16:94-103.

41. European Medicines Agency. European Surveillance of Veterinary Antimicrobial Consumption, Sales of veterinary antimicrobial agents in 30 European countries in 2016. EMA/275982/201. 2018.

42. Bundesamt für Verbraucherschutz und Lebensmittelsicherheit. Menge der abgegebenen Antibiotika in der Tiermedizin sinkt weiter. 2018. Available from: https://www.bvl.bund.de/DE/08_Presselnfothek/01_FuerJournalisten Presse/01_Pressemitteilungen/05_Tierarzneimittel/2018/2018_07_23_pi_ Antibiotikaabgabemenge2017.html. Last accessed 27.08.2019.

43. Federal Office of Consumer Protection and Food Safety. Federal Bulletin. BAnz AT; 2015. p. B11.

44. Federal Office of Consumer Protection and Food Safety. Federal Bulletin. BAnz AT; 2017. p. B4.

45. Schwarz S, Kehrenberg C, Walsh T. Use of antimicrobial agents in veterinary medicine and food animal production. Int J Antimicrob Agents. 2001;17:431-7.

46. Williams HE, Tokach MD, Dritz SS, Woodworth JC, DeRouchey JM, Nagaraja $\mathrm{TG}$, et al. Effects of chlortetracycline alone or in combination with direct fed microbials on nursery pig growth performance and antimicrobial resistance of fecal Escherichia coli. J Anim Sci. 2018;96:5166-78.

47. Pantozzi FL, Ibar MP, Nievas VF, Vigo GB, Moredo FA, Giacoboni GI. Wildtype minimal inhibitory concentration distributions in bacteria of animal origin in Argentina. Rev Argent Microbiol. 2014;46:34-40.

48. Burow E, Käsbohrer A. Risk factors for antimicrobial resistance in Escherichia coli in pigs receiving oral antimicrobial treatment: a systematic review. Microb Drug Resist. 2017;23:194-205.

49. Schulte-Oehlmann U, OehImann J, Püttmann W. Humanpharmakawirkstoffe in der Umwelt: Einträge, Vorkommen und der Versuch einer Bestandsaufnahme. UWSF. 2007;19:168-79.

50. Mah T-FC, O'toole GA. Mechanisms of biofilm resistance to antimicrobial agents. TIM. 2001;9:34-9.

51. Umweltbundesamt. Antibiotika und Antibiotikaresistenzen in der Umwelt. 2018.

52. Fairbrother JM, Nadeau É, Gyles CL. Escherichia coli in postweaning diarrhea in pigs: an update on bacterial types, pathogenesis, and prevention strategies. Anim Health Res Rev. 2005;6:17-39.

53. CLSI. Performance standards for antimicrobial disk and dilution susceptibility tests for Bacteria isolated from animals; second informational supplement. CLSI document VET01-S2. Clinical and Laboratory Standards Institute: Wayne, PA; 2013.

54. CLSI. Performance standards for antimicrobial disk and dilution susceptibility tests for Bacteria isolated from animals - fourth edition. CLSI document VET01-A4. Clinical and Laboratory Standards Institute: Wayne, PA; 2013.

55. Feßler AT, Böttner A, Fehr M, Kaspar H, Kehrenberg C, Kietzmann M, et al. Mikrotiterplattenlayouts für Kleintiere, Großtiere und Mastitis. DTBI. 2017;65:472-81.

56. NCCLS. Performance Standards for Antimicrobial Disk and Dilution Susceptibility Tests for Bacteria Isolated from Animals: Approved Standard Second Edition. NCCLS document M31-A2 [ISBN 1-56238-461-9]. 940 West Valley Road, Suite 1400, Wayne, Pennsylania 19087-1898 USA: NCCLS; 2002.

57. CLSI. Performance standards for antimicrobial disk and dilution susceptibility tests for Bacteria isolated from animals - fourth edition. CLSI supplement VET08. Clinical and Laboratory Standards Institute: Wayne, PA; 2018.

58. Deutsche Industrie Norm. Medical microbiology - Susceptibility testing of pathogens to antimicrobial agents - Part 8: Microdilution; General methodspecific requirements, NA 063 BR Beirat des DIN-Normenausschusses Medizin (NAMed): 2002. p. 10.

59. European Committee on Antimicrobial Susceptibility Testing - EUCAST. Data from the EUCAST MIC distribution website, 2019. Available from: http//nww.eucast.org. Last accessed 05082019

60. Ruddat I, Kadlec K, Schwarz S, Kreienbrock L. Statistische Verfahren zur Beschreibung von phänotypischen Empfindlichkeitsdaten. Berl Münch Tierärztl Wochenschr. 2014;127:349-58.

\section{Publisher's Note}

Springer Nature remains neutral with regard to jurisdictional claims in published maps and institutional affiliations. 